\title{
Literatura e politica numa letra só: Benjamin Abdala Junior, em perfil
}

\author{
Maged T. M. A. El Gebaly ${ }^{1}$
}

Professor, pesquisador, editor, crítico e atual coordenador de Letras e Linguística perante a Capes, Benjamin Abdala Junior tem sido um fervoroso crítico de toda classe de poder discricionário. Sua trajetória mostra como o velho e o falso dilema entre arte e política não deixa de ser um sofisma. "A politica, como outras formulações discursivas [diz-nos com convicção] são inerentes à própria codificação do texto literário". Constituem formulações que permitem entender o texto em suas articulações mais profundas. Desconsiderá-las, em função de uma pretensa literariedade é não permitir uma análise mais densa e contextualizada.

Dessa forma, tanto a elaboração do texto como sua leitura são enredadas por essas séries discursivas. Em relação à atualidade, falar em leitura politica pode implicar - como ele o faz - em se colocar contrariamente à distopia. Nada disso leva, entretanto, à desconsideração do sentido artístico da obra de arte. O que caracteriza um texto literário é sua capacidade de concentrar significações. Quanto melhor elaborado, mais vai resistir às leituras, e sua mensagem acaba por produzir impactos em leitores de muitas épocas.

Essa resistência faz com que encontremos novos significados ao curso de cada leitura de um mesmo texto, é nisto que reside o

\footnotetext{
1 Doutorando em Estudos Comparados de Literatura de Língua Portuguesa (DLCVFFLCH-USP). Bolsista CAPES-PEC-PG. Mestre em Lingüística (Seminário Andrés Bello - ICC)- Colômbia. Graduado em Tradução - Universidade de Ain Shams- Egito.
} 
pensamento de Benjamin Abdala Junior que gentilmente nos relatou como seu percurso, ainda nos tempos de graduação, sob a ditadura militar, foram marcados por estudos sociológicos, onde figurava Antonio Candido, Lucien Goldmann e Georg Lukács, entre outros. Em particular Erich Auerbach, autor de Mimesis: a Representação da Realidade na Literatura Ocidental, cuja grande lição foi mostrar como, a partir de um pequeno detalhe secundário do texto, é possivel caracterizar um modo de representar a realidade num determinado momento histórico. Sob o estímulo dos ensaios de Antonio Candido, Benjamin procurava verificar outra lição: como os fatores externos - da discursividade de outras áreas do conhecimento acabam se interiorizando e dando forma ao texto.

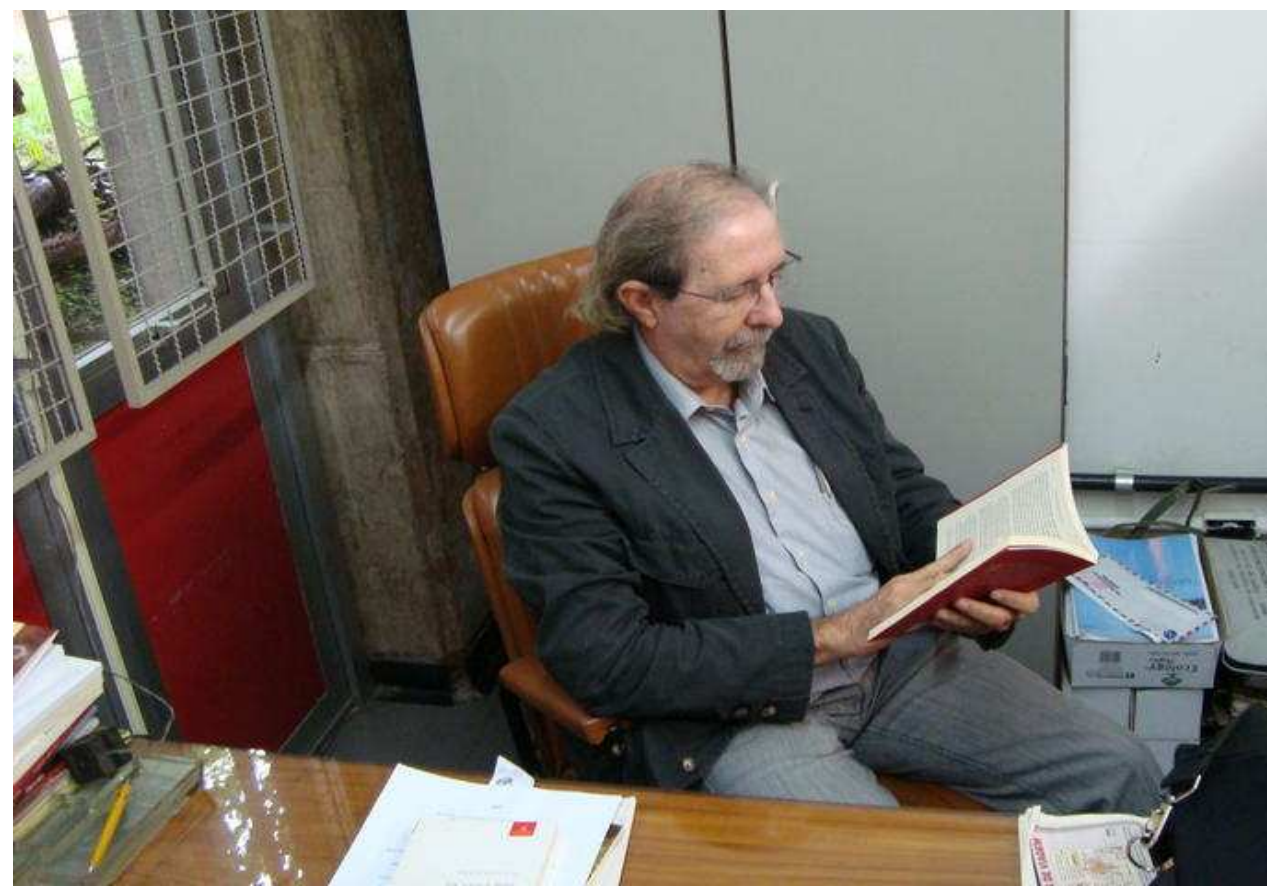

Foto: Maged T. M. A. El Gebaly

Dessas experiências de análise, veio a inclinação de Benjamin por procurar construir seu discurso crítico a partir de uma imagem literária, o que ocorreu em seu Mestrado e Doutorado. Para tanto, torna-se necessário dominar outras séries culturais, para discutir como concorrer para a construção da simbolização literária.

No livro A escrita neo-realista, o crítico defende um método de análise estilístico-estrutural, desenvolvendo bases encontradas na obra 
de Michael Riffaterre. Na obra Literatura, história e politica, projeto de livre-docência e extensão do seu tema do doutorado, e também em seu livro De vôos e ilhas, Benjamin estudou as formulações discursivas a partir de imagens. Sempre trabalhou no âmbito do comparatismo literário, em 1989 foi um dos fundadores da Associação Brasileira de Literatura Comparada e entre os anos de 1992-1994 ocupou o cargo de presidente da ABRALIC.

Saber de onde o crítico fala e quais são suas decorrências politicas sempre foram suas preocupações. Em seu livro Moderno de nascença, o Prof. Benjamin explica que nos finais da década de 50, o campo intelectual brasileiro discutia aquilo que nos faltava como nação independente. Surgiu, nessa atmosfera, o livro A formação da literatura brasileira. Há um gesto crítico que se configurou naquele momento. “Como este gesto crítico pode ser visto hoje?” interroga Benjamin. A situação mudou. Então qual é a situação do intelectual para desenhar atitudes similares e provocar impactos análogos ao de Antonio Candido e toda a sua geração. Como o intelectual se coloca diante isso?

Benjamin explica que após a crise do capitalismo financeiro, em 2008, o mundo entrou numa etapa de regulação, que vem acompanhada de discursos e práticas que visam à administração da diferença, que é importante para quem quer manter a hegemonia. Neste momento de repactualização, onde a influência dos blocos é notória, faz-se preciso que as diferenças sejam situadas de maneira crítica, em interações produtivas. Mais do que o respeito aos "outros", a convicção de se pode - e é interessante - aprender com esses "outros". Reciprocidade é o que importa.

Nessa perspectiva, ele discute tipos de formulações que levam ao choque de culturas, e que não reconhecem as realidades contemporâneas do hibridismo e das misturas culturais, que são cada vez mais intensas. Ele também se interessa por pesquisar como esses contatos todos podem se efetivar numa base mais produtiva que contemple as partes envolvidas com os mesmos direitos. 
É imprescindivel repensar o conceito de mestiçagem como no livro As Margens da Cultura. Trata-se de uma discussão iniciada no Segundo Império brasileiro e que chega aos países centrais, que só mais recentemente se deram conta dela. Em seu horizonte, procura focar processos de hibridação que realmente considerem os "outros". Estas seriam as personagens que vêm das margens e que entram como um ator de fato. Atualmente, nos estudos tradicionais do multiculturalismo na literatura, costumam aparecer vieses eurocêntricos, análogos àquela perspectiva do branqueamento, criticada por Frantz Fanon. Essa perspectiva está presente no discurso de aquiescência de Gilberto Freire, que tende à mestiçagem derivada dos valores eurocêntricos. Benjamin critica esta concepção de que: "Você é diferente, então eu o tolero, desde que você possa se aproximar de mim, dos meus valores”.

A diferença do outro, para Benjamin, não é a diferença do próprio. Segundo ele: "O diferente sempre é o outro. Hoje se vulgarizou falar do étnico: "isso aqui é uma beleza étnica! Uma moda étnica!. Quer dizer, étnico é o folclórico dos outros. Quando se tem algo do americano ou do europeu, isso não é étnico. O étnico é justamente o outro. É o latino. É o negro. Esse é o étnico. O branco não é o étnico".

O projeto atual de Benjamin volta-se para a discussão da posição do intelectual diante desta concepção do diferente. Ele procura uma diferença que coloque o outro em pé de igualdade. Ele quer respeito à diferença com base no reconhecimento das potencialidades do outro, e que é possivel aprender com a diferença do outro. Para ele, é central analisar como se efetiva a administração da diferença, suas articulações com toda a problemática da mestiçagem nos estudos sobre hibridismo cultural e como isso se traduz no texto literário.

O reconhecimento da diferença e das alteridades não é simplesmente uma posição teórica. Tanto dentro da USP como professor, ou na Capes como coordenador, Benjamin defende os programas de cooperação solidária Sul-Sul, nos quais, por exemplo, se um professor brasileiro trabalhar em cooperação em Cabo Verde ou Angola, ele não vai desenvolver uma forma de solidariedade, mas 
fundamentalmente de cooperação, pois ele vai aprender e vai voltar enriquecido pela experiência com outro. Neste sentido o professor Benjamin, como diretor Centro de Estudos de Literaturas de Língua Portuguesa na USP, organizou obras que criam pontes culturais como em Portos flutuantes - Trânsitos Ibero-afro-americanos.

Dentre os desafios que se colocam em termos politicos e de inovação, na Capes, estão os programas em rede, que podem abarcar países da América Latina. Os programas se articulam, com trocas de professores e alunos, tendo como objeto, por exemplo, escritores latinoamericanos. Um dos projetos de que participou foi o da sensibilização de adolescentes do Timor Leste para língua portuguesa. O presidente deste país, Xanana Gusmão, por meio de convênio firmado entre USP, MACKENZIE, PUC-SP E UNTL, pediu o apoio para o envio de alunos. Esse apoio consistiu no envio de 20 alunos que foram para o Timor Leste durante quatro meses a fim de desenvolverem um programa de sensibilização do aluno para a língua portuguesa através da canção popular brasileira. Os alunos executavam cantigas que continham letras, através das quais se discutiam questões ligadas à língua portuguesa e à cultura brasileira.

Benjamin sonha com a consolidação do projeto "Instituto Machado de Assis" cujos objetivos seriam: efetivar uma política externa em relação à língua, literatura e cultura brasileira; coordenar junto de Centros de Estudos Brasileiros no exterior e agenciar a implementação destes Centros em locais em que eles não existem.

Também quer no futuro programas de cooperação, que envolvam universidades árabes com universidades brasileiras para poder, efetivamente, manter toda uma interlocução em termos de literatura brasileira e de literaturas árabes. Ele pensa em cooperação com centros culturais capazes de promover um efetivo diálogo, onde os valores brasileiros sejam transmitidos e vice-versa.

Como vemos, a trajetória do professor Benjamin Abdala é coerente com a sua proposta. Quando começou a trabalhar na USP, acabou participando de alguns projetos editoriais importantes entre os 
anos 1977 e 1986 sobre literaturas de lingua portuguesa e critica literária. Entre os anos 1981 e 1982, dirigiu com Samira Youssef Campedelli uma série de livros chamada Literatura Comentada, que era produzida pela Editora Abril. Depois dessa experiência editorial, coordenou uma série de livros universitários para a Editora Ática. A preocupação do professor Benjamin não foi só nas instâncias da universidade, mas chegou também ao ensino fundamental e médio: para a coleção da Editora Scipione escreveu Introdução à análise narrativa que hoje é utilizada na biblioteca do professor das escolas públicas do país.

$\mathrm{Na}$ época, havia uma cultura da fotocópia, na qual eram utilizadas cópias de capítulos de livros estrangeiros, sem intervenção criativa por parte dos professores brasileiros. Benjamin sugeriu que os professores brasileiros publicassem livros dentro da série "Princípios", da editora Ática, que apresenta estudos com a ótica brasileira. Por exemplo, no estudo da narrativa, um professor escrevia um livro sobre a personagem; outro, sobre o foco narrativo; incorporando toda a bibliografia estrangeira; mas se apropriando, deglutindo aquilo em função da realidade brasileira e desenvolvendo uma bibliografia brasileira em termos teóricos e críticos.

Esse interesse pelo outro, pela diferença entendida em termos de experiência, tem a sua origem também nos caminhos de diversidade percorridos por ele ao longo da sua vida.

Benjamin Abdala Junior é descendente de árabes por parte do pai. A família da mãe, que é do sul de Minas imigrou para Uchoa, no interior do Estado de São Paulo. Seus avós paternos, de origem árabe (libanesa e síria), se conheceram no Brasil. Sempre manteve contatos afetivos por toda a política, história e cultura do mundo árabe, interessando-se pelos conflitos do Oriente Médio e a situação dos palestinos. Todo esse contato veio diretamente da convivência com amigos árabes.

Ele frequentou várias escolas estaduais, que na época eram as melhores. Já aos doze anos participava de um grupo de intelectuais, 
que Benjamin chamava a "turma do café" porque bebiam café falando de assuntos culturais. Nesta "turma" estava, entre outros, seu tio Jarbas Matos, que fazia o jornal da cidadezinha.

Em 1960 mudou-se para São Paulo para fazer o segundo cientifico no Colégio Estadual Presidente Roosevelt, no Ipiranga. No ensino secundário, teve acesso à literatura marxista inicialmente através dos livros de Erich Fromm, como "O conceito marxista do homem" e outros. Também participou da direção do centro acadêmico do seu colégio.

Depois, atuando profissionalmente no jornalismo, conheceu o movimento sindical e pode aprofundar-se na leitura de textos clássicos das áreas de sociologia e de politica. Foi-lhe importante um cursinho que fez com Hermínio Sachetta, onde leu Reforma ou Revolução de Rosa Luxemburgo. Na sequência, continuou lendo outros livros de Karl Marx como A ideologia alemã. Nessa época colaborou no Jornal das Ligas Camponesas, e a partir de 1964, começou a militar politicamente.

Em 1966, entrou no curso de Letras da USP. Seus paradigmas eram: Antônio Candido, Florestan Fernandes e Otavio Ianni. Na faculdade, ele teve amigos próximos que o ajudaram no crescimento intelectual, da mesma forma como ocorrera anteriormente com Armando Gimenes, que havia sido chefe de reportagem dos Diários Associados, onde trabalhou, e autor do primeiro livro sobre a Revolução Cubana publicado nas Américas, Sierra Maestra - A Revolução de Fidel Castro.

No ano de 1967, Benjamin foi eleito secretário geral do grêmio estudantil da Faculdade de Filosofia, Ciências e Letras. Passou, então, a dirigir o jornal do grêmio que era um semanário político com colaborações de intelectuais muito importantes na época, como Otto Maria Carpeaux e charges do Jaguar. Por pressões externas da própria polícia o jornal fechou. Em 1968, como professor de um colégio estadual, e já tendo deixado o jornalismo, participou da comissão organizadora de uma greve de professores. 
Depois do Ato Institucional N5, ficou preso de 1969 a inícios de 1971. Detido na Operação Bandeirantes, foi torturado por quinze dias e obrigado a se apresentar porque seu pai havia sido feito refém. Antes, já havia sido torturado no DOPS de São Paulo e levado para inquérito Policial Militar. Da Operação Bandeirantes, foi levado para o DOPS, onde ficou dois meses e meio em cárcere fechado e, de lá, para o Presídio Tiradentes. Foi condenado a um ano de detenção, após ter ficado um ano e quatro meses preso. Recorreu e foi absolvido.

Estavam no Presídio Tiradentes na ocasião, militantes contra a ditadura estabelecida no país sob feroz censura. Lá estavam estudantes, intelectuais e operários. Foi onde experimentou um modo de vida realmente comunitário entre os presos políticos. E também externamente, como a solidariedade de Maria Aparecida Santilli, sua professora de literatura portuguesa, que the mandava livros sobre o neorrealismo português, para que quando saísse, fizesse o mestrado com ela.

Em 1971 entrou no mestrado na USP, e em seguida conseguiu uma bolsa para ficar um ano em Portugal, onde foi recebido por escritores portugueses neorrealistas e antissalazaristas. Quando voltou, ao final de 1972, continuaram as perseguições.

Apesar de ter ganhado o concurso para ser professor da USP, sua nomeação demorou dois anos devido à triagem ideológica do Serviço Nacional de Informações que funcionava junto do gabinete do reitor. No entanto, Benjamin teve sempre grande apoio e solidariedade de Maria Aparecida Santilli, Antonio Candido, Nádia Battella Gotlib e Elza Miné. E também do professor Segismundo Spina, que foi à congregação reclamar a sua nomeação.

Sua postura, diante das tendências críticas saudosistas da literatura portuguesa, foi relevar autores que se contrapunham à ideologia salazarista. No mestrado, Benjamin estudou a literatura portuguesa com uma perspectiva brasileira contemporânea, sua comunicação em 1979 sobre "Novas técnicas de estudo da Literatura Portuguesa em nivel universitário" em uma mesa de abertura do VII 
Encontro de Professores Universitários Brasileiros de Literatura Portuguesa na UFMG, causou grande impacto ao apontar para os estudos comparados sob uma nova ótica. Estava em seu horizonte a perspectiva de que era importante buscar o que existe de brasileiro na cultura portuguesa e reciprocamente. No debate inflamado, outra professora - Dirce Cortes Riedel - alargou o comparatismo ainda mais: não apenas comparar só com Portugal, mas com França e com todas as outras literaturas. Assim, Benjamin desenvolveu a perspectiva que hoje dinamiza os estudos de literatura portuguesa no país. Após procurar laçadas em rede entre Brasil e Portugal, colaborou com sua orientadora Maria Aparecida Santilli, em seu pioneirismo nos estudos das Literaturas Africanas de Lingua Portuguesa no país.

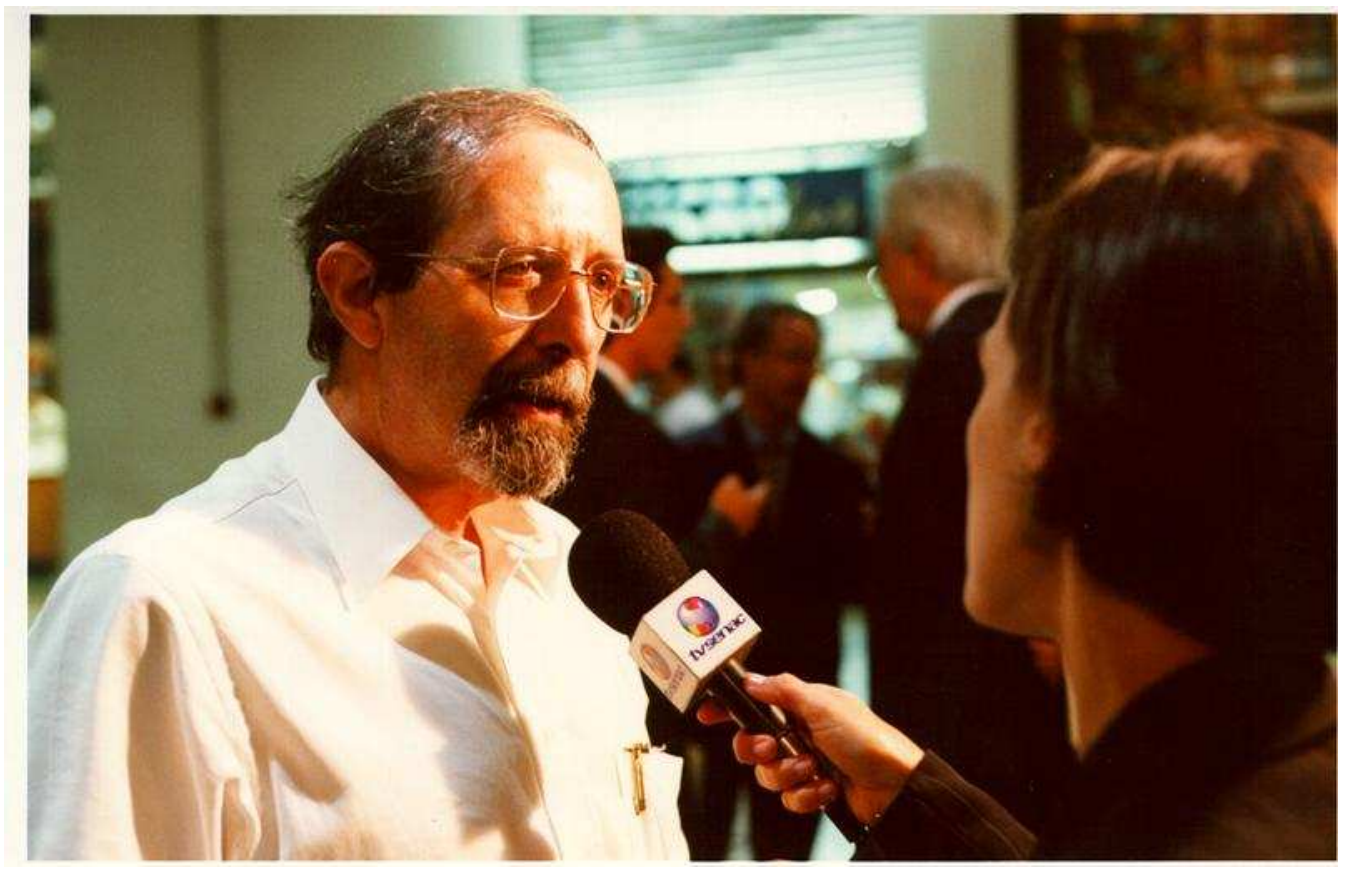

Foto: Editora Senac 
Benjamin explica que tem feito uma extensão análoga para os países de língua espanhola, que pode ser catalisada na imagem do "Algarve", da grande Andaluzia, que era um ponto de encontro entre a Europa, a África e o Mundo Árabe. Foi essa a primeira população que veio para as Américas, dando certa base até meados do século XVII. Era uma população culturalmente híbrida, diferente do norte europeu.

A trajetória diversa do Prof. Benjamin fez dele um ser humano livre, que luta pela interculturalidade, o que demonstra a inseparabilidade entre arte e política, entre forma e conteúdo, entre teoria e prática.

\section{Obras de Benjamin Abdala Junior}

Literaturas de Língua Portuguesa: Marcos e Marcas: Portugal. 2007

De vôos e ilhas. Literatura e comunitarismos. 2003

Fronteiras múltiplas, identidades plurais - um ensaio sobre mestiçagem e hibridismo cultural. 2002.

Introdução à Analise Narrativa. 1995.

Movimentos e Estilos Literários. 1994.

Contos Brasileiros. 1993.

O Romance Social Brasileiro. 1993.

Camões - Épica e Lírica. 1993.

Literatura, História e Política. 1988 e 2007

Tempos da Literatura Brasileira. 1985

Camilo Castelo Branco. 1984

Eça de Queirós. 1984

Historia Social da Literatura Portuguesa. 1982

A Escrita Neo-Realista. 1981 


\section{Obras organizadas e em co-autoria:}

ABDALA JUNIOR, B. (Org.) e CARA, S. A. (Org.) Moderno de nascença: figurações críticas do Brasil, 2006.

Margens da cultura: mestiçagens, hibridismo \& outras misturas, 2004.

Antero de Quental, cidadão e poeta: a esperança como princípio. In: Benjamin Abdala Junior. (Org.). Melhores poemas de Antero de Quental, 2004.

ABDALA JUNIOR, B. (Org.) e SCARPELLI, M. O. F. (Org.). Portos flutuantes. Trânsitos ibero-afro-americanos, 2004.

Incertas relações. Brasil e Portugal no século XX, 2003. ABDALA JUNIOR, B. (Org.) e MOTA, L. D. (Org.) . Personae: grandes personagens da literatura brasileira, 2001. Ecos do Brasil. Eça de Queirós, leituras brasileiras e portuguesas, 2000.

ABDALA JUNIOR, B. e ALEXANDRE, I. Canudos - Palavra de Deus, Sonho da Terra, 1997. 